\title{
THE IMPACT OF THE AUTOMOTIVE INDUSTRY ON THE MOROCCAN ECONOMY
}

\author{
Rania Echriguii, \\ Adil Moghar, \\ Mhamed Hamiche \\ Department of Economics and Management, \\ Abdelmalek Essaâdi University, \\ Morocco
}

\begin{abstract}
:
This study explains the relationship between the Moroccan automotive industry, employment and gross domestic product GDP, for this reason, a literature review on the subject was conducted, which allowed us to understand the relationship between all variables. After the analysis, the results show that the variables integration order allowed us to apply the error correction model (ECM), in fact, this model confirmed the relationships between the variables, and showed that the automotive industry in Morocco has a significant positive impact on employment and GDP.
\end{abstract}

JEL: L60; L62

Keywords: automotive industry, economic growth, employment, domestic growth

\section{Introduction}

The commercial opening and financial liberalization adopted these last years by many countries, allowed some emerging economies, based on the availability of important factors of production, to develop new sectors of activities strongly competitive by redeploying the efforts for the installation the automobile industries, electronics and aeronautics, thus allowing these countries to find their place in the new world industrial order.

Morocco is also part of this strategy of trade liberalization. and search for investments in new global trades that bring growth, and which could, among other things, mitigate the trade deficit that continues to increase over the past ten years. The main initiative taken in this context is the Emergence Plan which is based on two complementary dimensions namely a management of the existing fabric and a proactive

i Correspondence: email echrigui.rania@gmail.com, adilmoghar@gmail.com, hamiche2020@gmail.com 
targeting on the engines of growth around the automotive, electronics, aerospace and offshoring as well as the so-called traditional sectors, textiles, leather and food.

This study is part of the studies on the evaluation related to industrial strategy, in particular, the automotive industry in Morocco which is a subject of current debate for several reasons: Internationally, this sector is evolving in a context of increased competition between the main global poles. In addition, the effects of the economic crisis on the automotive industry (regression of sales in Europe and the United States) have contributed to the displacement of part of the European production to emerging countries and focus on low-cost brands by adapting to the new global market that leads major manufacturers to seek new production areas with more competitive advantages. Currently, the global automotive sector is undergoing a phase of reorganization of its chain value with a shift in global demand and supply towards emerging countries.

This new restructuring of the global chain value has led to a significant redeployment of production capacity between the major geographical areas in favor of the emerging countries, with Asia's share rising from 36\% to 52\% between 2003 and 2013, and to a lesser extent South America (from 3\% to 5\%), compared with a decline in the share of the advanced economies: from 33\% to $23 \%$ for Europe and from $24 \%$ to $15 \%$ for North America.

In terms of demand, there is also a strong emergence of Asia, driven by the economic and demographic powers (China, India), with an average annual growth rate of $10 \%$, followed by South America (9\% per year) and Africa (5\%), against a decline in demand from advanced economies with $-2 \%$ per year for Europe and $-1 \%$ per year for North America.i

This new structuring of demand has prompted manufacturers to look for new locations in countries with a competitive global offer (proximity to major markets, logistics offer, qualified workforce, etc.), to better adapt to the specific demands of new emerging markets.

At the national level, and outside the traditional sectors, the Moroccan automotive industry is considered the key sector of the new global trades in terms of export performance achieved in recent years, thanks to direct foreign investment in this sector, without forgetting also the resistance of the Moroccan automotive industry to the economic crisis whose fallout has not affected the segment of automotive manufacturing even if its effect has been felt on domestic equipment manufacturers.

In this new context, the Moroccan automotive industry strengthens its position in the global automotive chain value as evidenced by the remarkable performance recorded in recent years with an automotive production exceeding 227,570 vehicles in 2014 against only 18,546 vehicles in 2003.

Morocco has become the second largest producer of vehicles in Africa after South Africa with a market share of 35\% in 2014 against 5\% in 2003, and which should be further strengthened with the entry into service of the second tranche of the Renault project bringing its total capacity to 340,000 vehicles. Corollary, the sector's exports have crossed

\footnotetext{
ii World Bank
} 
the mark of 40 billion dirhams in 2014 rising, thus, to the first rank of export activities. The Renault plant in Tanger has also celebrated, on May 5, 2015, the release of its 400,000th vehicle since the launch of its activity in February 2012.

This positioning of Morocco on the global chain value has established the sector as a true global business, around which a set of efforts has been made to promote a coherent and attractive automotive offer based on efficient logistics around the TangierMed port, a targeted training offer, dedicated industrial infrastructure, as well as aid to installation. In this context and following an in-depth analysis of the new deal of the sector and its changes at the global level, this study proposes to focus on the situation of the sector at the national level (performance, analysis of the offer ...) and its positioning in the global automotive map. It will allow, subsequently, following the lessons drawn from some successful foreign experiences in the matter, to propose ways of progress for the development of a competitive national automotive offer and better integrated in the world chain value. Our research will attempt to answer the following central question:

- What is the impact of the evolution of the automobile sector on the Moroccan economy?

This question gives rise to two hypotheses to be tested, in order to verify the rethinking elements of our main problem.

H1: The evolution of productivity in the automotive sector impacts employment in Morocco.

H2: The productivity of the automotive sector impacts the growth of the Moroccan economy.

This paper will focus on the impact of the Moroccan automotive industry on employment and economic growth.

\section{Literature review}

A few empirical studies have been conducted to examine the relationship between car sales and various macroeconomic variables. The results are generally mixed. Based on the review of this research, several factors have been identified as potentially influencing car sales.

Dynaquest (2002) found that there was a strong relationship between automotive sector production and nominal GDP, just as there was a relationship between the total number of cars manufactured and nominal GDP. However, the correlation between new car sales and nominal GDP is not as strong as the relationship between the total number of cars used and GDP.

According to Automotive Research Smith and Chen (2009), a historical correlation between annualized GDP and vehicle production growth in the U.S. indicates that positive vehicle production growth depends on at least 3\% of GDP growth. Therefore, a decrease in vehicle production can be expected if the annualized GDP growth rate is less than $1.0 \%$. In general, only GDP above 3.0 is associated with output growth. These results show that there is a significant relationship between GDP and the automotive industry in the United States. 
According to Babatsou and Zervas (2011), it is clear that there is a good correlation between GDP and passenger car production in the European. The results of this study clearly show that the number of vehicles increases with GDP, indicating a very good linear correlation $(r=0.95)$. This clearly indicates that a decline in GDP will lead to a decline in the total number of vehicles used.

Kongs berg Automotive (2008) analyzed the relationship between world car production and world GDP from 1998 to 2008. The results show that there is a strong correlation between the global automotive industry and global GDP. Other factors analyzed are income level, interest rate, financial aggregate, unemployment rate, employment, Foreign Direct Investment (FDI) and export. These include the research by Shahabudin (2009) on domestic and foreign sales of products. In this research, it was found that all variables could significantly influence the sales and production of cars. However, this regression model suffered from heteroscedasticity that affected the efficiency of measuring domestic and foreign car sales and production.

In his research, it is proven that all variables can significantly influence the automotive sector. However, the problem of heteroscedasticity had compromised the efficiency of the model as a whole.

Ludvigson (1998) tested the impact of financial policy on car sales and production pula which was attributed to the provision of bank loans for car purchases. The increase in the base interest rate was found to have a significant negative impact on car sales. This is due to the lack of capacity of commercial banks to offer loans to car buyers.

Chifurira et al (2014) their object of study is to examine the impact of inflation on automobile production in South Africa over the sample period of 1969 to 2013. The results of the study indicate that there is a unidirectional causal effect (one-way causality) of inflation to vehicle productions.

Muhammad et al. (2012) following their research to analyze the impact of economic variables on automobile production in five ASEAN countries. The long-run and short-run correlation between these variables is implemented using the panel error correction model. The annual data from 1996 to 2010 for five variables from five ASEAN countries, namely Malaysia, Singapore, Thailand, Philippines and Thailand, were collected as a sample for their research. The test result shows that gross domestic product (GDP), inflation (CPI), unemployment rate (UNEMP) and loan rate (LR) are significantly correlated in the long run with new car production and sales in these ASEAN countries. The value of the short-run error correction to achieve long-term stability based on the ECT parameter is found to be significant in Malaysia, Singapore, and Thailand. Furthermore, each country is influenced by different short-term variables.

\section{Study of variables}

\subsection{Choice of variables}

The objective of our study is to analyze the impact of the productivity of automotive sector on the evolution of growth and employment. We have two variables to explain the growth (GDP) of manufacturing industry and employment, noted (PRO) and (EMP), then 
we try to know if a good growth of the production of automotive sector, leads to an increase in GDP or employment.

\subsection{Graphical analysis of series}

The graphical analysis allows us to determine some statistic properties of the series.

The graphical representation of the (EMP) series is characterized by an upward trend which allows us to say that the (EMP) series is non-stationary. The data generating model is multiplicative.

Figure 1: Evolution of the variation of the series (EMP)



Source: HCP

Figure 2: Evolution of the variation of the series (GDP) in million Dhs

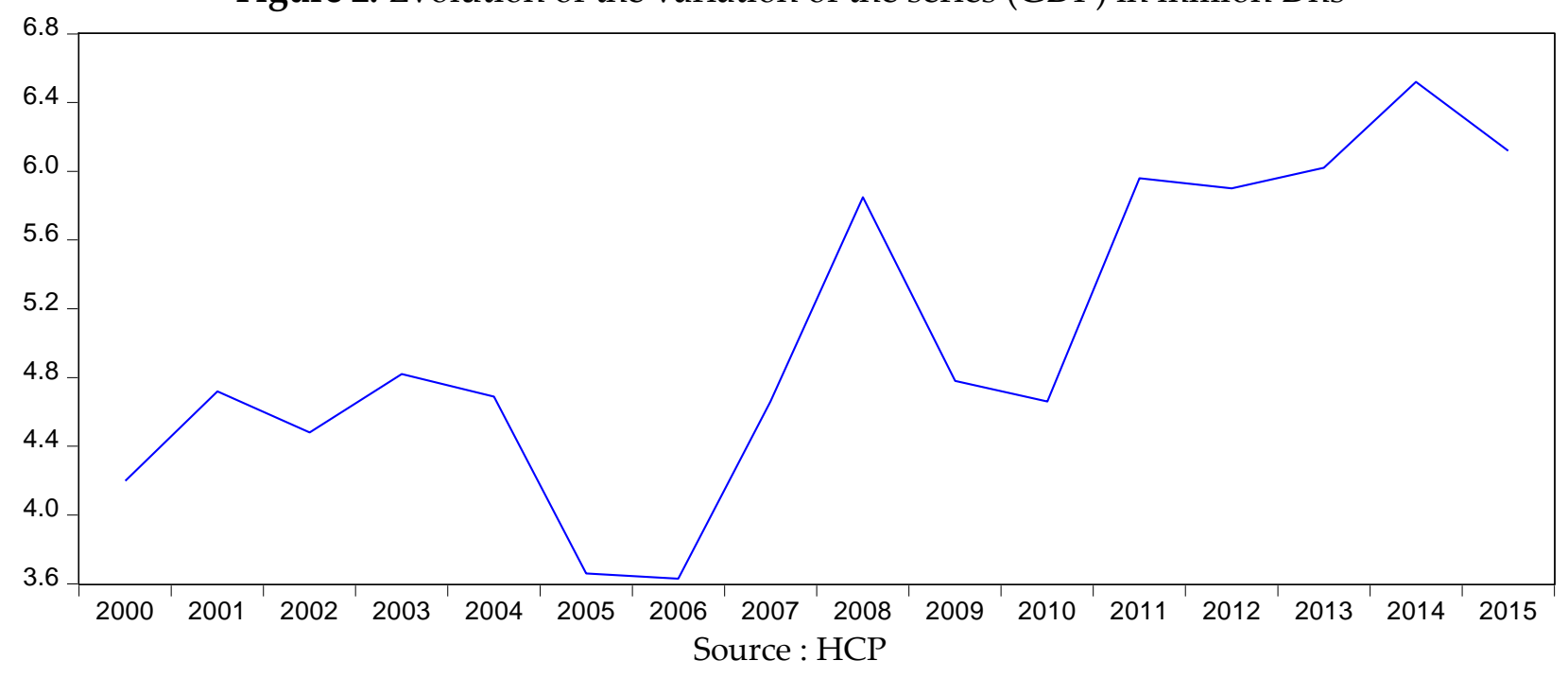

From the graph we can see that the (GDP) series is characterized by an upward trend which explains the non-stationarity of the (GDP) series, and generated by a multiplicative model. 


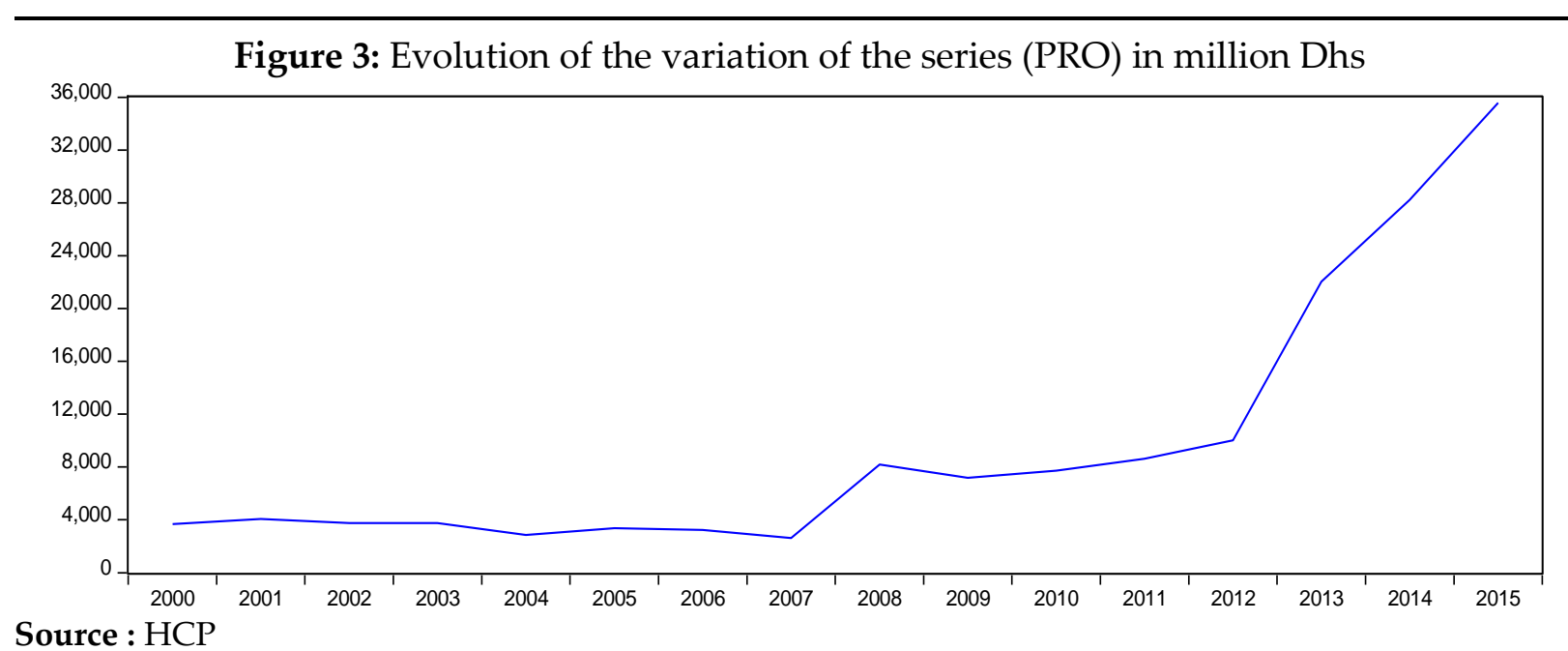

We find that the production of the automotive sector has a progressive upward trend, so it is characterized by small disturbances, which allows us to see that the series (PRO) is non-stationary, and generated by a multiplicative model.

\subsection{Logarithmic transformation of variables}

The elasticity coefficient measures the increase of a variable in relation to the variations of another variable. The interest is obvious, it allows the forecaster to understand the impact of the variation of a variable on another. The variables are previously transformed by applying logarithms and as the elasticity coefficient is a ratio of logarithmic derivatives, the regression coefficient(s) can be directly interpreted as the elasticity coefficient(s).

Figure 4: Evolution of series variations (LPIB, LPRO, LEMP)

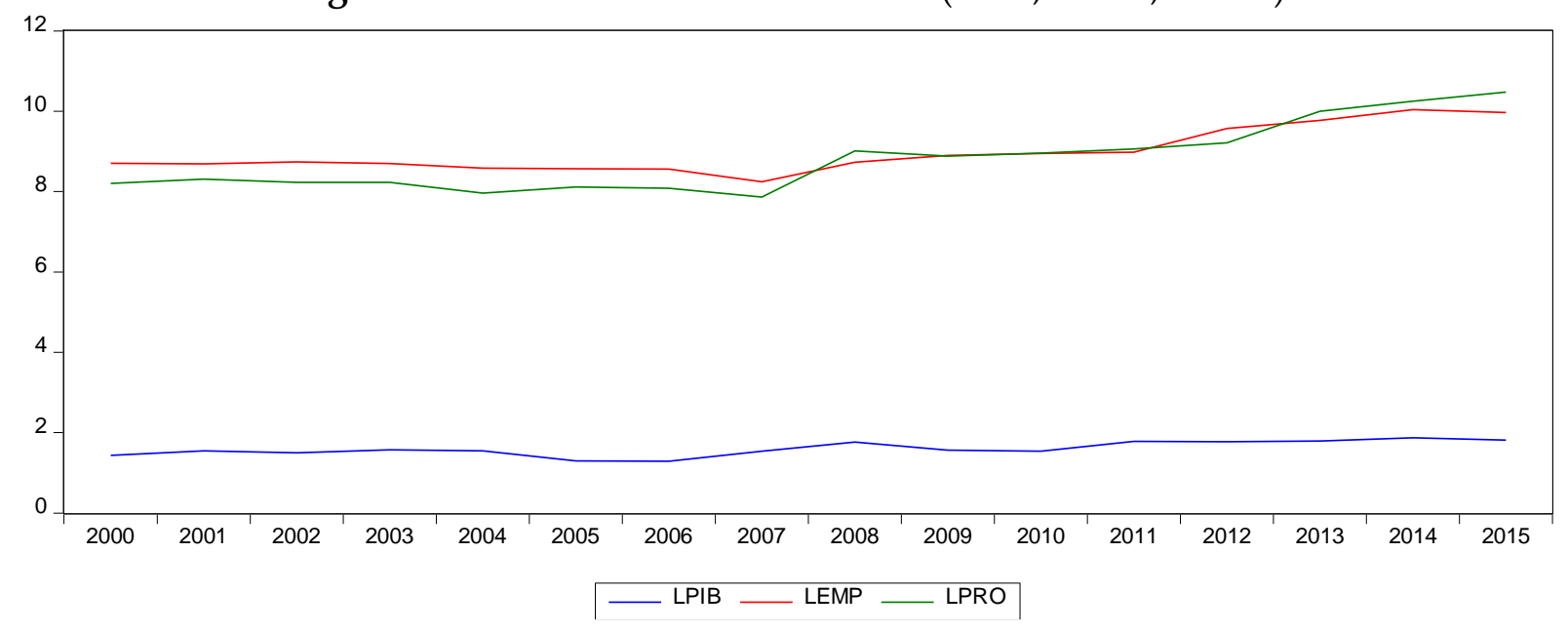

In the following part of this study, the variables used are the following (LPIB, LPRO, LEMP). The Figure 4 shows the evolution of the series of variables after logarithmic transformation. 


\subsection{Descriptive statistics of variables}

Table 1: Descriptive statistics of variables

\begin{tabular}{|l|c|c|c|}
\hline & LPIB & LPRO & LEMP \\
\hline Medium & 1.602617 & 8.803318 & 8.979792 \\
\hline Median & 1.558125 & 8.595959 & 8.730928 \\
\hline Maximum & 1.874874 & 10.47923 & 10.03933 \\
\hline The minimum & 1.289233 & 7.866339 & 8.242756 \\
\hline Standard deviation & 0.180914 & 0.835315 & 0.546893 \\
\hline Skewness & -0.16141 & 0.792921 & 0.903229 \\
\hline Kurtosis & 2.041433 & 2.410788 & 2.483834 \\
\hline & & & \\
\hline Jarque-Bera & 0.682045 & 1.908046 & 2.353144 \\
\hline Probability & 0.711043 & 0.385188 & 0.308334 \\
\hline Sum & 25.64188 & 140.8531 & 143.6767 \\
\hline Sum Sq. Dev. & 0.490948 & 10.46626 & 4.486375 \\
\hline Observations & 16 & 16 & 16 \\
\hline
\end{tabular}

The above table shows that LPRO is more volatile than other variables, and GDP is less volatile in terms of standard deviation. Also, we note that the variables under study are not normally distributed (Prob. Jarque-Bera $>5 \%$ ).

\subsection{The study of the stationarity of the series}

Through the graphical analysis of the previous series, we could see the non-stationarity of the series. To verify the stationarity of the series, we will apply the Dickey Fuller unit root test. This test will also allow us to determine the number of lags of all variables. Before applying this test, we will first recall the basic principles of stationary and nonstationary time series.

\subsubsection{Stationary and non-stationary series}

A series $\left\{y_{t}\right\}$ for $t=1, \ldots, T$ is said to be stationary if :

1) $E(y t)=\mu \forall T$ (Constant does not depend on $t)$.

2) $\operatorname{Var}\left(y_{t}\right)=\sigma_{y}^{2} \forall t$ (Constant, does not depend on $\mathrm{t}$ )

3) $\operatorname{Cov}\left(y_{t}, y_{t+k}\right)=E\left[\left(y_{t}-\mu\right)\left(y_{t+k}-\mu\right)\right]=y_{t}$ (Do not disengage from $\mathrm{t}$ ).

The series $\left\{\varepsilon_{t}\right\}$ of which $E\left(\varepsilon_{t}\right)=0, \operatorname{Var}\left(\varepsilon_{t}\right)=\sigma_{\varepsilon}^{2}, \operatorname{Cov}\left(\varepsilon_{t}, \varepsilon_{t+k}\right)=0$, is a stationary series also called white noise.

As opposed to a stationary process, a non-stationary process is a process that does not satisfy one of the conditions mentioned above. To analyze the non-stationarity of a series, two processes are distinguished: the TS (Trend stationary) process and the DS (Difference stationary) process.

\subsubsection{The TS process}

The TS (Trend stationary) process is written: $y_{t}=f(t)+\varepsilon_{t}$ where $\mathrm{f}$ is a function of time and $\varepsilon_{t}$ A stationary process with zero mean and constant variance. This process is nonstationary because. $E\left(y_{t}\right)=\alpha+\beta_{t}$ Depends on time t. It can be stationary by 
subtracting from $y_{t}$ the estimated values of $\alpha$ and of $\beta$ by the ordinary least squares OLS method.

\subsubsection{The DS process}

The DS (Difference Stationary) process with drift is expressed as follows:

$y_{t}=y_{t-1}+\beta+\varepsilon_{t}$ This process is non-stationary, because $E\left(y_{t}\right)=y_{0}+\beta_{t}$.

The DS process without drift (random walk) is written as $y_{t}=y_{t-1}+\varepsilon_{t}$. It is nonstationary, because the variance of this process depends on time t. $\operatorname{Var}\left(y_{t}\right)=t \sigma_{\varepsilon}^{2}$. To stationaryize the DS process with or without drift, it is sufficient to pass it in first difference:

$y_{t}-y_{t-1}=\beta+\varepsilon_{t}($ Case with drift $)$

Were

$y_{t}-y_{t-1}=\varepsilon_{t}$ (Case without drift).

\subsection{Operating principles of the augmented Dickey-Fuller test}

The Dickey Fuller test is used to determine whether a series is stationary or not, and it also determines the correct way to stationary the series. This test does not assume that $\varepsilon_{t}$ of the series as being white noise. The assumptions of this test are defined as follows:

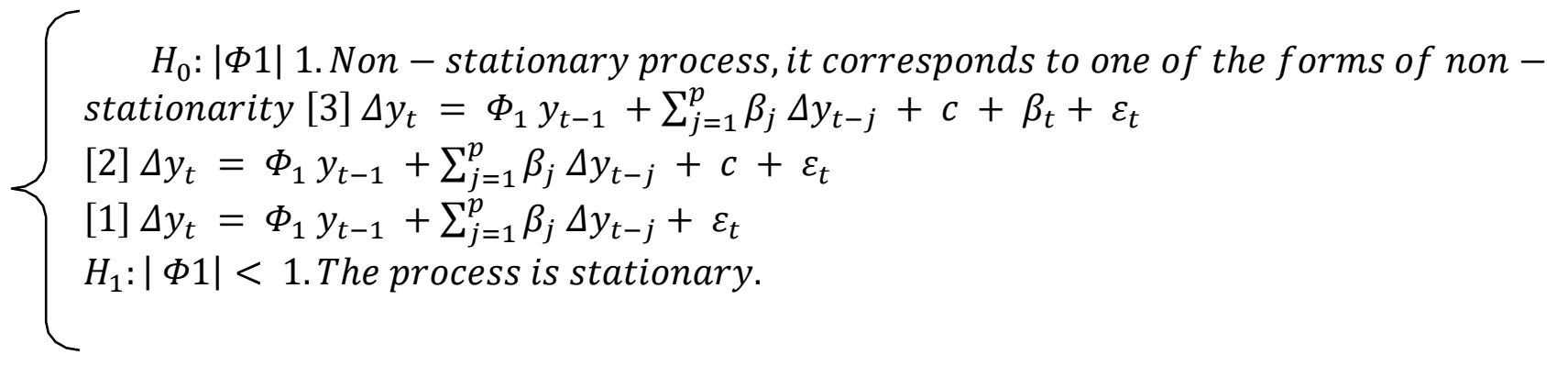

We estimate by OLS the parameter $\Phi$ for the three models [1], [2] and [3]. This estimation gives us the coefficients and the standard deviations of the three models. It provides the ADF statistic $(t \Phi)$.

The decision rule is as follows:

- If $\mathrm{t} \Phi_{1}>\mathrm{t}$ tabulated: we accept $\mathrm{H} 0:|\Phi 1|=1 \rightarrow$ the series is not stationary.

- If $\mathrm{t} \Phi_{1}<\mathrm{t}$ tabulated: we accept $\mathrm{H} 1:|\Phi 1|<1 \rightarrow$ the series is stationary. 
Table 2: ADF stationarity test for the series to be studied

\begin{tabular}{|c|c|c|c|c|c|c|c|c|c|}
\hline \multicolumn{10}{|c|}{ Test of Dickey Fuller increased } \\
\hline \multirow[b]{2}{*}{ Variables } & \multicolumn{3}{|c|}{ Model 1} & \multicolumn{3}{|c|}{ Model 2} & \multicolumn{3}{|c|}{ Model 3} \\
\hline & $\begin{array}{c}\text { ADF } \\
\text { Statistics }\end{array}$ & $\begin{array}{c}\text { Critical } \\
\text { value }\end{array}$ & Probability & $\begin{array}{c}\text { ADF } \\
\text { Statistics }\end{array}$ & $\begin{array}{l}\text { Critical } \\
\text { value }\end{array}$ & Probability & $\begin{array}{c}\text { ADF } \\
\text { Statistics }\end{array}$ & $\begin{array}{c}\text { Critical } \\
\text { value }\end{array}$ & Probability \\
\hline \multicolumn{10}{|c|}{ Test in level } \\
\hline LEMP & 0.227918 & -3.9591 & 0.9647 & -1.365955 & -4.7284 & 0.8277 & 0.227918 & -3.9591 & 0.9647 \\
\hline LPIB & -0.432264 & -4.0579 & 0.8760 & -3.276002 & -4.8000 & 0.1107 & 1.075916 & -2.7549 & 0.9161 \\
\hline LPRO & 0.330207 & -3.9591 & 0.9715 & -1.628052 & -4.7283 & 0.7317 & 1.608594 & -2.7282 & 0.9668 \\
\hline \multicolumn{10}{|c|}{ Test in first difference } \\
\hline LEMP & $-3.4371^{* *}$ & -4.0044 & 0.0276 & -3.436906 & -4.9922 & 0.0934 & $-3.122673^{*}$ & -2.7406 & 0.0044 \\
\hline LPIB & $-4.74674^{*}$ & -4.0579 & 0.0031 & -4.58422 & -4.8864 & 0.0158 & -4.5589 & -2.7549 & 0.0002 \\
\hline LPRO & $-4.22785^{*}$ & -4.0044 & 0.0067 & $-5.16143^{*}$ & -4.8000 & 0.0057 & $-3.675317^{*}$ & -2.7406 & 0.0013 \\
\hline
\end{tabular}

*stationary at $1 \%$ level ${ }^{* *}$ stationary at $5 \%$ level

Source: Based on Eviews 10 results.

The stationarity tests show that at the $1 \%$ level the variables (LEMP, LPIB, LPRO) are not stationary in the level Test in model 1 (with constant term), in model 2 (with constant term and linear trend) and in model 3 (without constant term and without linear trend). On the other hand, the first difference stationarity tests show that the series are stationary for the three models. We conclude that the variables LPIB, LEMP and LPRO are integrated I (1).

\section{Estimation of the error correction model (ECM)}

ECM model estimation is done in two steps:

Step 1: OLS estimation of the long-run relationship:

$$
y_{t}=\hat{\alpha}+\hat{\beta} x_{t}+e_{t}(E C M)[1]
$$

Step 2: OLS estimation of the dynamic model relationship (short run):

$$
y_{t}=\alpha_{1} \Delta x_{t}+\alpha_{2} e_{t-1}+u_{t} \alpha_{2}<0[2]
$$

The coefficient $\alpha_{2}$ (return to equilibrium) must be significantly negative; otherwise, an ECM-type specification should be rejected. Indeed, the error correction mechanism (catching up to the long-run relationship) would then go in the opposite direction and move away from the long-run target.

The two-step procedure leads to a convergent estimate of the model's coefficients, and the standard deviations of the coefficients can be interpreted in the classical way (Engle and Granger, 1987). The estimation of an error-correction model does not therefore pose any particular problem and simply requires the use of an ordinary least square's technique. In the case of additional explanatory variables for which the cointegration hypothesis cannot be retained (such as indicator variables, for example), the estimation procedure is the same except for the estimation of the model [1] (long-run equation) in which these explanatory variables are included. 
- OLS estimation of the long-run relationship of the LEMP variable

The following model explains the long-run relationship between the employment variable and the output of the automotive sector the model equation is written as follows:

$$
L E M P=\hat{\alpha}+\widehat{\beta} L P R O+e_{t}
$$

Table 3: OLS estimation of the long-run relationship of the variable 'EMP'

\begin{tabular}{|l|c|c|c|c|}
\hline Variable & Coefficient & Std. Error & t-Statistic & Prob. \\
\hline C & 3.491788 & 0.472665 & 7.38745 & 0.00 \\
\hline LPRO & 0.623402 & 0.053467 & 11.65967 & 0.00 \\
\hline F-statistic & \multicolumn{3}{|l}{135.9479} & 0.00 \\
\hline
\end{tabular}

\begin{tabular}{|l|l|}
\hline R-squared & 0.906634 \\
\hline Durbin-Watson stat & 1.367522 \\
\hline
\end{tabular}

It appears from this table that the estimated model is significant, the Durbin-Watson statistic is greater than the $\mathrm{R}^{2}$ statistic which means that the model is valid, as well as the probability value of the explanatory variable LPRO is less than 0.05 which indicates that the coefficient of this variable is statistically significant and explains the variable LEMP The long-run model equation is written as follows:

$$
L E M P=3.491788+0.623402 L P R O+e_{t}
$$

We can say that an increase in production by 1-point results in an increase in employment by 0.62 points.

- OLS estimation of the short-run relationship of the LEMP variable

The following model explains the short-run dynamic relationship between the employment variable and the output of the automotive sector the model equation is written as follows:

$$
L E M P=\alpha_{1} \Delta L P R O+\alpha_{2} e_{t-1}+u_{t} \alpha_{2}<0
$$

Table 4: OLS estimates of the short- run relationship of the variable 'EMP'

\begin{tabular}{|l|c|c|c|c|}
\hline Variable & Coefficient & Std. Error & T-Statistic & Prob. \\
\hline C & 0.021592 & 0.044325 & 0.48714 & 0.635 \\
\hline D(LPRO) & 0.429222 & 0.115144 & 3.727706 & 0.003 \\
\hline U (-1) & -0.63361 & 0.247995 & -2.55491 & 0.025 \\
\hline F-statistic & \multicolumn{3}{|l}{9.004524} & 0.004 \\
\hline
\end{tabular}

\begin{tabular}{|l|c|}
\hline R-squared & 0.600121 \\
\hline Durbin-Watson stat & 1.855394 \\
\hline
\end{tabular}

The results of estimation of dynamic model in the short run confirm the validity of our model, the Durbin-Watson statistic is higher than the value of $\mathrm{R}^{2}, 0.600121<1.855394$. 
Moreover, the probability of the coefficients of the explanatory variables is lower than 0.05 which confirms the validity of the model.

The short-run model equation is written as follows:

$$
D L E M P=0.021592+0.429222 D L P R O+-0.63361 U(-1)
$$

The coefficient of the residual variable of the long- run model $U$ is negative, this variable expresses the speed of return to the long- run model, in our case it is -0.633 .

Table 5: Serial correlation test of short- run model

\begin{tabular}{|l|c|l|c|}
\hline \multicolumn{3}{|l|}{ Breusch-Godfrey Serial Correlation LM Test: } & 0.682 \\
\hline F-statistic & 0.397815 & Prob. F (2,10) & 0.575 \\
\hline Obs*R-squared & 1.10549 & Prob. Chi-Square (2) & 0.575 \\
\hline
\end{tabular}

For the short- run model, the Breusch-Godfrey serial correlation test confirms the absence of serial correlation between the variables, this result is confirmed by the probability value of F-statistic which is greater than 0.05 .

- OLS estimation of the long-run relationship of the LPIB variable

The following model explains the long-run relationship between the LPIB variable and the production of the automotive sector, the model equation is written as follows:

$$
L P I B=\hat{\alpha}+\widehat{\beta} L P R O+e_{t}
$$

Table 6: OLS estimation of the long- run relationship of the variable 'EMP'

\begin{tabular}{|l|c|c|c|c|}
\hline Variable & Coefficient & Std. Error & T-Statistic & Prob. \\
\hline C & 0.041342 & 0.293719 & 0.140753 & 0.8901 \\
\hline LPRO & 0.177351 & 0.033225 & 5.337919 & 0.0001 \\
\hline F-statistic & & 28.49338 & 0.000105 \\
\hline
\end{tabular}

\begin{tabular}{|l|c|}
\hline R-squared & 0.670537 \\
\hline Durbin-Watson stat & 1.792028 \\
\hline
\end{tabular}

It emerges from this table that the estimated model is significant, the Durbin-Watson statistic is greater than that of $\mathrm{R}^{2}$ which means that the model is correct, and the probability value of the explanatory variable LPRO is less than 0.05 which indicates that the coefficient of this variable is statistically significant and explains the variable LPIB The long-run model equation is written as follows:

$$
L P I B=0.041342+0.177351 L P R O+e_{t}
$$

We can say that an increase in GDP by 1-point results in an increase in production by 0.17 points. 
- OLS estimation of the short-run relationship of the LPIB variable

The following model explains the short-run dynamic relationship between the LPIB variable and the output of the automotive sector the model equation is written as follows:

$$
L P I B=\alpha_{1} \Delta L P R O+\alpha_{2} e_{t-1}+u_{t} \alpha_{2}<0
$$

Table 7: OLS estimation of the short-run relationship of the variable 'LPIB'

\begin{tabular}{|l|c|c|c|c|}
\hline Variable & Coefficient & Std. Error & T-Statistic & Prob. \\
\hline C & -0.00087 & 0.032046 & -0.02726 & 0.9787 \\
\hline D(LPRO) & 0.209273 & 0.088488 & 2.365003 & 0.0357 \\
\hline U (-1) & -0.97315 & 0.313431 & -3.10484 & 0.0091 \\
\hline F-statistic & 5.6537 & 0.018626 \\
\hline
\end{tabular}

\begin{tabular}{|l|c|}
\hline R-squared & 0.485142 \\
\hline Durbin-Watson stat & 1.848103 \\
\hline
\end{tabular}

The short-run dynamic model estimation confirms the validity of our model, the DurbinWatson statistic is greater than the $\mathrm{R}^{2}$ value, $0.485142<1.848103$. Still, the coefficients probabilities of the explanatory variables are lower than 0.05 , which confirms the validity of the model.

The short-run model equation is written as follows:

$$
D L P I B=-0.00087+0.209273 D L P R O-0.97315 U(-1)
$$

The return coefficient to the long-run model in this case is -0.97315 .

Table 10: Serial correlation test of short-run model

\begin{tabular}{|l|c|l|c|}
\hline \multicolumn{4}{|l|}{ Breusch-Godfrey Serial Correlation LM Test: } \\
\hline F-statistic & 3.95089 & Prob. F (2,10) & 0.0544 \\
\hline Obs*R-squared & 6.620945 & Prob. Chi-Square (2) & 0.0365 \\
\hline
\end{tabular}

For the short-run model, the Breusch-Godfrey serial correlation test confirms the absence of serial correlation between the variables, the same result is confirmed by the F-statistic probability value.

\section{Economic interpretation of results}

The Moroccan market offers significant development prospects, particularly given that the level of new vehicle sales is half that of its Algerian neighbor for an equivalent population. The relatively dense Moroccan industrial fabric is made up mainly of automotive suppliers and equipment manufacturers specializing in high labor cost activities (wiring, sheet metal), which is also a weakness insofar as more capital-intensive activities are not very present in this country. 
In addition to exports of parts and equipment to the European Union, the Moroccan market, initially oriented towards the national market in terms of vehicles built, is also tending to turn towards regional markets and the Middle East.

Morocco also has the only assembly line in the Maghreb for commercial and passenger vehicles, SOMACA. It is in this plant that Renault vehicles (the "Logan" and the "Kangoo") and PSA vehicles ("Partner" and "Berlingo") are assembled.

Investment revenues from the automotive industry have grown strongly in recent years. They rose from 683 million dirhams in 2008 to 508 million dirhams in 2013, with a peak of more than 5.5 billion dirhams in 2011 and 3.4 billion dirhams in 2011. Exports of the automotive sector have recorded in recent years a remarkable performance from 889 million dirhams in 2007 to over 28 billion dirhams in 2015, an average annual growth rate of $22 \%$. Several advantages have attracted foreign investors, the low cost of labor, tax benefits and state support for this new industry, which is a new alternative for growth for the Moroccan economy.

In this paper we tried to explain the relationship between the production of automotive sector and their impact on the Moroccan economy. First, the impact of the automotive sector on employment and then the impact of this sector on the gross domestic product. To do so, we approached the problem as an empirical study, the model chosen was the ECM, this choice was explained by the order of integration of our variables, as well as the literature review dismaying this subject.

The results of the tests showed that our model is significant, and it allows to explain the relationship between the variables of our study, the first model that estimates the relationship between employment and production of the automotive sector confirmed that a positive variation in production also generates a positive variation in the number of labor employed, the coefficient of model in the long run is 0.623402 , while for the short run model is 0.429222 , both models, long and short run confirm the positive relationship between employment and production of the Moroccan automotive sector, it is observed that the long run impact is the most powerful for this model.

For the second model which explains the relationship between the growth of industrial sector "GDP" and the production of automotive sector, the estimation of the ECM and also significant, the long-run model shows a positive relationship between the production and the growth of GDP, the model coefficient is 0.17735 , while for the shortrun model, it is 0.209273 which confirms that the impact of short run is more powerful than that of the long run.

\section{Conclusion}

At the beginning of this paper, we developed a literature review related to our problematic, multiple studies have tried to explain the relations between the automotive sector and the growth and development of the economy in general. Our empirical study was based on the ECM model, this choice was explained by the integration order of the variables. The results of our study confirmed the two hypotheses. The automotive industry in Morocco has a significant positive impact on GDP and employment. 


\section{Conflict of Interest Statement}

I certify that I have NO affiliations with or involvement in any organization or entity with any financial interest (such as honoraria; educational grants; participation in speakers' bureaus; membership, employment, consultancies, stock ownership, or other equity interest; and expert testimony or patent-licensing arrangements), or non-financial interest (such as personal or professional relationships, affiliations, knowledge or beliefs) in the subject matter or materials discussed in this manuscript.

\section{About the Authors}

Rania Echrigui, First year PhD student at university Abdelmalek Essaadi, Tétouan. Specialize in machine learning and its application in finance.

Adil Moghar, PhD student at university Abdelmalek Essadi, Tétouan. Author of many articles in several domains such as, artificial intelligence, portfolio optimization, environmental studies and finance and banking.

Mhamed Hamiche, Professor at Abdelmalek Essadi, Tétouan. Author of a large number of articles in different domains, finance, logistic, human resources, management marketing and generals economic.

\section{References}

DynaquestSdnBhd (2002). Update on a section of the Motor Vehicle Report on BSAIndustry Overview, Prospect, Directors and Management.

Smith, Brett and Chen, Yen (2009). The Major Determinants of US Automotive Demand: Factors driving US Automotive Market and Their Implications for Specialty Equipment and Performance Aftermarket Suppliers, Center for Automotive Research.

Babatsou, Christina and Zervas, Efthimios (2011). EU Socioeconomic Indicators and Car Market, World Academy of Science, Engineering and Technology.

Shahabudin, Syed, (2009). Forecasting automobile sales, Management Research News, 32:7, pp. 670-682.

Sydney Ludvigson (1998). The Channel of Monetary Transmission to Demand: Evidence from the Market for Automobile Credit, Journal of Money, Credit and Banking, 30:3, pp. 365-383.

Chifurira, R., Mudhombo, I., Chokobvu, M., and Dubihlela, D. (2014). The Impact of Inflation on the Automobile Sales in South Africa, ISSN 2039-2117, vol. 5, No. 7, pp: 200-207.

Muhammad, F., Hussin, M. Y. M., \&Razak, A. A. (2012). Automobile Sales and Macroeconomic Variables: A Pooled Mean Group

Engle, R. F., \& Granger, C. W. (1987). Co-integration and error correction: representation, estimation, and testing. Econometrica: journal of the Econometric Society, 251-276. 
Rania Echrigui, Adil Moghar, Mhamed Hamiche

THE IMPACT OF THE AUTOMOTIVE INDUSTRY ON THE MOROCCAN ECONOMY

Creative Commons licensing terms

Authors will retain copyright to their published articles agreeing that a Creative Commons Attribution 4.0 International License (CC BY 4.0) terms will be applied to their work. Under the terms of this license, no permission is required from the author(s) or publisher for members of the community to copy, distribute, transmit or adapt the article content, providing a proper, prominent and unambiguous attribution to the authors in a manner that makes clear that the materials are being reused under permission of a Creative Commons License. Views, opinions and conclusions expressed in this research article are views, opinions and conclusions of the author(s). Open Access Publishing Group and European Journal of Economic and Financial Research shall not be responsible or answerable for any loss, damage or liability caused in relation to/arising out of conflict of interests, copyright violations and inappropriate or inaccurate use of any kind content related or integrated on the research work. All the published works are meeting the Open Access Publishing requirements and can be freely accessed, shared, modified, distributed and used in educational, commercial and non-commercial purposes under a Creative Commons Attribution 4.0 International License (CC BY 4.0). 